\title{
"Every day I think about your messages": assessing text messaging engagement among Latino smokers in a mobile cessation program
}

This article was published in the following Dove Press journal: Patient Preference and Adherence

\author{
Francisco \\ Cartujano-Barrera' \\ Evelyn Arana-Chicas' \\ Mariana Ramírez-Mantilla ${ }^{2}$ \\ Jaime Perales ${ }^{2}$ \\ Lisa Sanderson Cox ${ }^{2}$ \\ Edward F Ellerbeck ${ }^{2}$ \\ Delwyn Catley ${ }^{3}$ \\ Ana Paula Cupertino' \\ 'Department of Cancer Prevention and \\ Control, Hackensack University Medical \\ Center, Hackensack, NJ, USA; \\ ${ }^{2}$ Department of Preventive Medicine and \\ Public Health, University of Kansas \\ Medical Center, Kansas City, KS, USA; \\ ${ }^{3}$ Center for Children's Healthy Lifestyles \\ \& Nutrition, Children's Mercy Kansas \\ City, Kansas City, MO, USA
}

Correspondence: Francisco CartujanoBarrera

Department of Cancer Prevention and Control, Hackensack University Medical

Center, 107 Ist Street, Building B,

Hackensack, NJ 0760I, USA

Tel + I 55I 9964242

Email francisco.cartujano@hackensackmeridian.org
Introduction: Mobile health interventions are a promising mode to address tobacco-related disparities among Latinos, the largest minority group and the highest users of text messaging technology. The purpose of this pilot study was to assess engagement in a smoking cessation intervention delivered via text message (Kick Buts) among Latino smokers.

Methods: We relied on a community-based recruitment strategy to enroll 20 Latino smokers in Kick Buts. Outcome measures included biochemically verified abstinence at 12 weeks, participant text messaging interactivity with the program, and satisfaction.

Results: Participants' mean age was 40.7 years old ( $\mathrm{SD}=14.6)$. Most of the participants were male $(70 \%)$, did not have health insurance $(75 \%)$, and reported low nicotine-dependence $(60 \%)$. The majority of participants $(75 \%)$ sent at least one text message to the program. On average, participants who interacted with the program sent $31.8(\mathrm{SD}=39.7)$ text messages. Eight themes were identified in participants' messages (eg, well-being, self-efficacy, strategies to quit, extra-treatment social support, etc). At 12 weeks, $30 \%$ of the participants were biochemically verified as abstinent.

Conclusion: A smoking cessation text message intervention generated high engagement among Latinos and resulted in noteworthy cessation rates. Future studies should assess the relationship of text messaging interactions with psychological effects (eg, intra-treatment social support, therapeutic alliance, and perceived autonomy support).

Keywords: Latinos, smoking, smoking cessation, text messages, m-Health

\section{Introduction}

Of the approximately 55 million Latinos that reside in the USA, over 6 million $(11.2 \%)$ are current smokers. ${ }^{1}$ Latino smokers are less likely than non-Hispanic whites to have access to health care and resources for smoking cessation, receive advice to quit, and use pharmacotherapy to stop smoking. ${ }^{2,3}$ Despite these marked tobacco-related disparities, there is a lack of efficacious interventions designed for Latino smokers, particularly interventions that have the potential for broad reach in the Latino community. Overcoming these disparities demands affordable, accessible, effective, and culturally congruent solutions.

Evidence supports the effectiveness of smoking cessation interventions delivered via text messaging. ${ }^{4-9}$ Developments in the sophistication of mobile technologies allow for flexible delivery of text messages, with algorithms used to tailor content to individual motivational and behavioral needs for smoking cessation. ${ }^{10}$ Furthermore, the potential for text messages to deliver smoking cessation treatment 
may be even greater among hard-to-reach, socioeconomically disadvantaged, and uninsured populations, ${ }^{5}$ such as Latinos. However, implementation of mobile interventions among Latinos remains minimal despite the fact that Latinos are the largest minority group in the $\mathrm{USA}^{11}$ and the highest users of text messaging technology. ${ }^{12}$ The purpose of this pilot study was to assess engagement in a smoking cessation intervention delivered via text messages (Kick Buts) among Latino smokers.

\section{Methods}

\section{Sample}

Latino smokers were recruited using a community-based approach. In May 2015, community health workers recruited 20 Latino smokers from venues with high concentration of Latinos (supermarkets, safety-net clinics, community centers, and churches).

Eligible participants 1) identified as Latino, 2) were $\geq 18$ years of age, 3 ) smoked a minimum of 5 days in the past week, ${ }^{13}$ 4) had an active mobile phone, and 5) were ready to quit smoking in the next 30 days. Individuals were excluded if 1) they were pregnant, breastfeeding or planning to do so in the following year, or 2) they were planning to move from the study area within the next 6 months. Written informed consent was obtained from each participant. The study was approved by the University of Kansas Medical Center IRB committee.

\section{Intervention}

Kick Buts is an adaptation of Txt2stop, a smoking cessation text message intervention that demonstrated a twofold increase in abstinence among program participants. ${ }^{7,8}$ Kick Buts draws on principles from the Social Cognitive Theory ${ }^{14}$ comprising motivational messages, behavioral-change support, and pharmacotherapy use (Nicotine Replacement Therapy). Kick Buts was available in English and Spanish, and allowed three levels of interactivity:

1. Pre-scheduled standard messages. Messages were automatically tailored to the participant's name(s) and selected quit-date. Text messages were organized along a 12-week timeline designed to support a personalized quit plan: 1) Pre-quit (14 days); 2) Quit-day (1 day); 3) Post-quit Intensive (28 days); and 4) Post-quit Maintenance (8 weeks).

2. Keyword-triggered standard messages. These messages consisted of automated immediate responses sent to participants who texted one of the following keywords: Crave, Stress, Alcohol, Slip Up, and Relapse. Participants could withdraw from the text message program at any moment by sending the keyword Stop.

3. Counselor personalized responses. The Kick Buts intervention had the capability to recognize free texting (non-keyword) from participants. A trained research staff monitored and triaged queries daily, responding within $24 \mathrm{hrs}$ of receipt of text messages sent by participants.

The initial pre-scheduled and keyword-triggered standard messages were developed by a multidisciplinary team that included a sample of young adults and health researchers with expertise in adolescent health, nutrition, cognitive behavioral therapy, and smoking cessation. ${ }^{8}$

\section{Measures}

Research staff conducted a baseline and a 12-week follow-up assessment in person. The baseline survey included sociodemographic characteristics, nicotine dependence, quitting history, and readiness to quit. Text messaging use was monitored to estimate frequency, length, and content, as well as the use of keywords throughout the entire intervention (12 weeks). At the in person 12-week follow-up visit, we assessed text message engagement, satisfaction, and cessation outcomes. The cessation outcome was cotinine-verified 7day point prevalence abstinence (no cigarettes in the past 7 days). This was biochemically verified using salivary cotinine testing, with a cutoff of $15 \mathrm{ng} / \mathrm{mL} .^{15}$ Satisfaction measures included questions such as "How satisfied are you with the smoking cessation text message program?"

\section{Analysis}

Frequencies, means, and standard deviations were calculated for all variables. Participants' text messages were imported into Microsoft Excel for qualitative thematic analysis. Two bilingual coders independently analyzed the data using a process of inductive thematic analysis. ${ }^{16}$ Subsequently, themes were grouped into coding themes and a code map was developed. ${ }^{17}$ The two coders met weekly and compared findings to identify similarities and differences with the codes. A third bilingual coder joined for in-depth discussion if differences in coding were found between the two coders. ${ }^{16}$ 


\section{Results}

Participants' mean age was 40.7 years old $(\mathrm{SD}=14.6)$. Most of the participants were male (70\%) and did not have health insurance (75\%). Less than half of the participants had not completed high school (45\%). More than half $(65 \%)$ reported only speaking Spanish at home, and almost all participants (95\%) chose the intervention to be delivered in Spanish. All participants were daily smokers, $75 \%$ were light smokers $(<10 \mathrm{CPD})$, and $60 \%$ were classified as low nicotine-dependence according to the Fagerström Test for Nicotine Dependence ${ }^{18}$ (Table 1).

During the 12-week intervention period, levels of engagement varied among participants: $5(25 \%)$ participants never interacted with the program, $7(35 \%)$ had a low interaction (1-9 messages), 4 (20\%) had a medium interaction (10-49 messages), $2(10 \%)$ had a high interaction (50-99 messages), and $2(10 \%)$ had a very high interaction ( $\geq 100$ messages). Participants who interacted with the program at least once had on average 31.8 $(\mathrm{SD}=39.7)$ interactions. Of the 478 messages that participants sent to the program, only 23 messages (4.8\%) used keywords.

Participant engagement varied across the different stages of the program (see Figure 1). Engagement with the program increased in the days around the quit-date, and progressively decreased overtime. Other interactive peaks were related to specific prompts that pertained to quitting status (eg, on Day 28: "It's been 4 weeks, do you continue to be smoke-free? Let us know. Respond YES or NO to this text"). Four (20\%) participants texted the keyword Stop to disenroll from the program. Disenrollment happened at different time points of the intervention $(8,9$, 72 , and 83 days after the quit-date).

When analyzing the length of all text messages sent by participants, most $(n=349,73.0 \%)$ had more than 30 characters (eg, "I have multiple reasons to quit smoking. My main reasons are my health and my little daughter", “... everything is going well. Yesterday I didn't smoke for the first time in my life! I'm doing great!').

When analyzing the content of all text messages sent by participants, eight themes were identified. The five most common themes included: 1) Well-being (26.1\%) (eg, "Now I'm feeling so much better, I can feel my improvement. Thanks for your help"); 2) Self-efficacy (18.6\%) (eg, "I'm capable and I can make it, we can make it"); 3) Strategies to Quit (17.0\%) (eg, "I go on a walk with my daughter every day to keep my mind away
Table I Baseline characteristics of participants $(n=20)$

\begin{tabular}{|c|c|}
\hline Characteristics & n (\%) \\
\hline Age, mean (SD) & $40.7(14.6)$ \\
\hline \multicolumn{2}{|l|}{ Sex } \\
\hline Male & 14 (70\%) \\
\hline Female & $6(30 \%)$ \\
\hline \multicolumn{2}{|l|}{ Education level } \\
\hline Less than high school graduate & $9(45 \%)$ \\
\hline High school graduate or GED & 7 (35\%) \\
\hline Technical school & $2(10 \%)$ \\
\hline College graduate & $2(10 \%)$ \\
\hline \multicolumn{2}{|l|}{ Marital status } \\
\hline Married/cohabitating & $10(50 \%)$ \\
\hline Single & $4(20 \%)$ \\
\hline Divorced/separated/widowed & $6(30 \%)$ \\
\hline \multicolumn{2}{|l|}{ Health insurance coverage } \\
\hline No health coverage & $15(75 \%)$ \\
\hline Employer & $3(15 \%)$ \\
\hline Private & $\mathrm{I}(5 \%)$ \\
\hline Medicaid/Medicare & $\mathrm{I}(5 \%)$ \\
\hline \multicolumn{2}{|l|}{ Smoking pattern } \\
\hline Daily, I-9 CPD & $15(75 \%)$ \\
\hline Daily, 10-19 CPD & $2(10 \%)$ \\
\hline Daily, 20 or more CPD & $3(15 \%)$ \\
\hline \multicolumn{2}{|l|}{ Fagerström Test for Nicotine Dependence } \\
\hline Minimally dependent & $12(60 \%)$ \\
\hline Moderately dependent & $7(35 \%)$ \\
\hline Highly dependent & I (5\%) \\
\hline \multicolumn{2}{|l|}{ Attempted quitting previous year } \\
\hline Yes & $15(75 \%)$ \\
\hline No & $5(25 \%)$ \\
\hline \multicolumn{2}{|l|}{ Language Spoken at Home } \\
\hline Only Spanish & $13(65 \%)$ \\
\hline More Spanish than English & $4(20 \%)$ \\
\hline Both equally & $2(10 \%)$ \\
\hline More English than Spanish & $\mathrm{I}(5 \%)$ \\
\hline \multicolumn{2}{|l|}{ Language chosen for the intervention } \\
\hline Spanish & 19 (95\%) \\
\hline English & I (5\%) \\
\hline
\end{tabular}

Abbreviations: $\mathrm{CPD}=$ Cigarettes per day; $\mathrm{GED}=$ General educational development test.

from smoking"); 4) Extra-treatment Social Support $(12.3 \%)$ (eg, "I told my boss I'm quitting smoking, he's really happy ..."); and 5) Reasons to Quit (10.3\%) (eg, "I fight this for my family and my health") (See Table 2). Importantly, some participants responded to pre-scheduled messages as if they were interacting with a live person and 


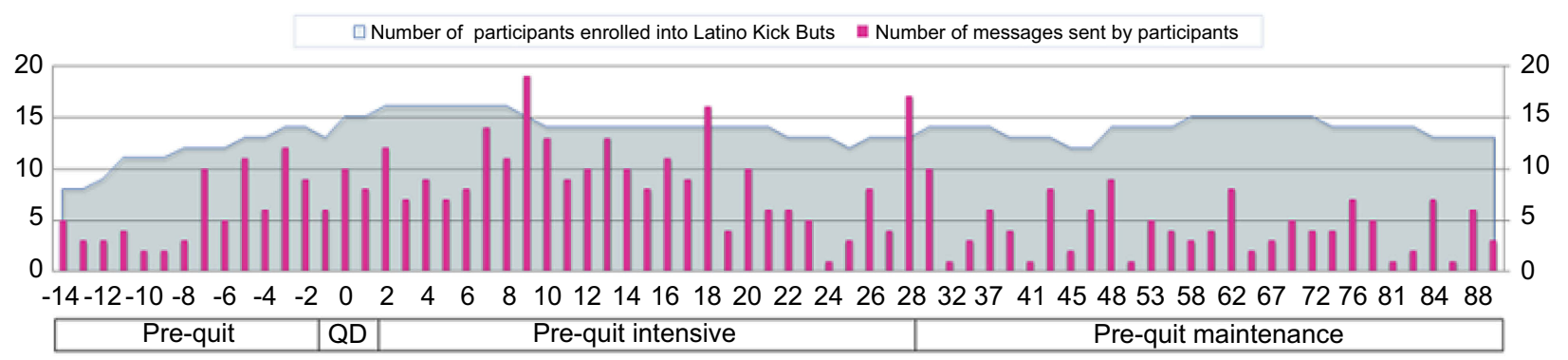

Figure I Number of text messages sent by participants during the I2-week intervention.

Abbreviation: QD= Quit Day.

not with an automatic text message software (eg, "Every day I think about your messages ... ", "I'm sorry for not replying sooner, I was working ...").

Seventeen participants completed the 12-week followup survey ( $85 \%$ retention rate). Using intention-to-treat analysis, self-reported 7-day point prevalence abstinence was $30 \%$ among the participants. All saliva samples of the participants that self-reported having quit read below the limit of quantification for cotinine. When asked about program satisfaction, $70.5 \%$ reported being very satisfied and all participants reported that they would use the program again in the future if available. Participants recommended that 1) study staff should reply immediately to their text messages, 2) text messages should further address social support (engagement of family, friends, and ex-smokers), and 3) the Spanish translation should be improved. Of the participants who disenrolled from the text message program $(n=4), 2(50 \%)$ reported quitting smoking and therefore no longer required the program's services. These two participants were cotinine-verified abstinent.

\section{Discussion}

To the best of our knowledge, this is the first study reporting text messaging interactivity among Latinos smokers enrolled in a text messaging smoking cessation program. Kick Buts was well received by participants, most of whom engaged in high levels of interactivity with the program (bi-directional messaging) and reported high levels of participant satisfaction. The high levels of interactivity with the program can be partly attributable to the fact that Latinos are the highest users of text messages across racial and ethnic groups. ${ }^{12}$ Compared to three studies that assessed participant engagement in a smoking cessation text message program, Latinos in this study interacted at higher levels (31.8 text messages during a 12 -week period). Abroms et al found that among a mostly
non-Hispanic sample of smokers, those who interacted at least once sent an average of $11.8^{19}$ and $28.4^{9}$ text messages during a 6-month period. It is important to note that these two studies' interactivity was keyword-based. Cupertino et al found that among a sample of smokers in Mexico, participants sent an average of 21 text messages during a 12 -week period; and only $11.3 \%$ of the text messages used keywords. ${ }^{20}$ Similar to the study conducted in Mexico, participants in this study preferred to send their own, self-composed text messages rather than relying on keywords from the program for a response. This suggests that reliance on keywords may be insufficient for smoking cessation counseling via text messaging among Latinos. Hence, there may be additional costs involved in having trained personnel responding to participants' text messages, as occurred in our study. Participants' text messages can also guide the creation of a categorized codebook that would be able to retrieve and send responses automatically, thus reducing the need for trained personnel responding to participants' text messages. Analysis of participants' text message content in our study revealed the most common themes were well-being, self-efficacy, use of coping strategies and social support, and reasons for quitting. Automated messages targeted to these topics might be most effective at promoting engagement of Latino smokers.

Given that $30 \%$ of participants were biochemically verified smoking abstinent, Latino smokers could potentially benefit from self-composed text message interactions because of the psychological effects (eg, intra-treatment social support, strong therapeutic alliance, and perceived autonomy support).

This study had a number of limitations that should be considered when interpreting the findings. This was a pilot study with a small sample size $(n=20)$ and did not have a control group. Follow-up was limited to a single assessment at the end of treatment at 12 weeks. As only $5 \%$ of 
Table 2 Content of participant-generated text messages

\begin{tabular}{|c|c|}
\hline Theme & Selected quotes from participants \\
\hline \multirow[t]{3}{*}{ Wellbeing } & $\begin{array}{l}\text { Latino Kick Buts ( } 19 \text { days after the quit-day): Food tastes better, your taste is improved. These are benefits of quitting smoking } \\
\text { Male, } 53 \text { years old: "Now I'm feeling so much better, I can feel my improvement. Thanks for your help" }\end{array}$ \\
\hline & $\begin{array}{l}\text { Latino Kick Buts ( I day after the quit-day): Today there will be cravings. Resist them, over time it will be easier. Keep } \\
\text { your mind and hands busy } \\
\text { Male, } 53 \text { years old: Thank you! Everything is going well. Yesterday I didn't smoke for the first time in my life! I'm doing great! }\end{array}$ \\
\hline & $\begin{array}{l}\text { Latino Kick Buts ( } 28 \text { days after the quit-day): You made it, } 4 \text { weeks! You feel better and you are saving } \$ \text {. Celebrate. } \\
\text { Congrats for a month without smoking } \\
\text { Male, } 23 \text { years old: Today I feel great. I'm experiencing a new life, a nonsmoking life }\end{array}$ \\
\hline \multirow[t]{3}{*}{ Self-efficacy } & $\begin{array}{l}\text { Latino Kick Buts ( } 18 \text { days after the quit-day): Ex-smokers say that the } 3 \text { rd week is the hardest. If you relapsed, don't } \\
\text { worry, keep going. Stay strong } \\
\text { Male, } 23 \text { years old: Yes, I'm strong! I am capable! I am incredible! I will make it! }\end{array}$ \\
\hline & $\begin{array}{l}\text { Latino Kick Buts ( } 9 \text { days after the quit-day): Celebrate each day that you're smoke-free. Bask in the triumph and feel } \\
\text { proud of liberating yourself from smoking. } \\
\text { Male, } 49 \text { years old: I feel very proud of whom I am today because now I'm respecting myself }\end{array}$ \\
\hline & $\begin{array}{l}\text { Latino Kick Buts ( } 9 \text { days after the quit-day): Success=falling seven times, getting up } 8 \text { times, Japanese proverb. Relapses } \\
\text { will help you learn what works for you. Keep going. } \\
\text { Male, } 49 \text { years old: I feel I have more strength than three people put together. I won't relapse. }\end{array}$ \\
\hline \multirow[t]{3}{*}{ Strategies to Quit } & $\begin{array}{l}\text { Latino Kick Buts (I day after the quit-day): Write in a journal about your progress in quitting smoking. } \\
\text { Male, } 53 \text { years old: I go on a walk with my daughter every day for staying smoke-free }\end{array}$ \\
\hline & $\begin{array}{l}\text { Latino Kick Buts ( } 4 \text { days after the quit-day): Myth=smoking helps you concentrate. No. It is a drug and in } 15 \text { mins you } \\
\text { will want another one. You are concentrating on the next cigarette. } \\
\text { Male, } 55 \text { years old: I've been keeping myself busy to stay away from cigarettes. It's working! }\end{array}$ \\
\hline & $\begin{array}{l}\text { Latino Kick Buts ( } 3 \text { days before the quit-day): Put reminders everywhere: "I am strong", “I have decided”, "I can give up the } \\
\text { habit". } \\
\text { Female, } 45 \text { years old: I posted a picture of two ugly smoker's lungs at my fridge. Let's see if it helps me quit smoking }\end{array}$ \\
\hline \multirow[t]{3}{*}{$\begin{array}{l}\text { Extra-treatment Social } \\
\text { Support }\end{array}$} & $\begin{array}{l}\text { Latino Kick Buts ( } 2 \text { days before the quit-day): Have you told someone that you will quit smoking so that they can } \\
\text { support you? } \\
\text { Female, } 43 \text { years old: I told my boss. He's really happy. This morning the first thing he said was: another day without smoking? }\end{array}$ \\
\hline & $\begin{array}{l}\text { Latino Kick Buts ( } 12 \text { days after the quit-day): Resort to your friends and family for support. When you have urges to } \\
\text { smoke, send a short text asking them how they are doing. } \\
\text { Male, } 55 \text { years old: Yes, I've been in touch with my family every day since I quitted smoking }\end{array}$ \\
\hline & $\begin{array}{l}\text { Latino Kick Buts ( } 79 \text { days after the quit-day): Visualize yourself as a non-smoker. When you are offered a cigarette, say } \\
\text { NO! I don't smoke. For sure they will say: well done! } \\
\text { Male, } 49 \text { years old: My friends don't offer me cigarettes any more, they know l'm a non-smoker }\end{array}$ \\
\hline \multirow[t]{3}{*}{ Reasons to Quit } & $\begin{array}{l}\text { Latino Kick Buts (I I days before the quit-day): Do you think quitting is very important? Make a list of the pros to keep } \\
\text { you motivated. } \\
\text { Male, } 53 \text { years old: I have multiple reasons to quit smoking. My main reasons are my health and my little daughter }\end{array}$ \\
\hline & $\begin{array}{l}\text { Latino Kick Buts ( } 6 \text { days after the quit-day): What is your most important reason to quit smoking? Write them in big } \\
\text { letters and put them in a place where you can see them. } \\
\text { Male, } 55 \text { years old: I want to quit smoking to improve my health }\end{array}$ \\
\hline & $\begin{array}{l}\text { Latino Kick Buts ( } 32 \text { days after the quit-day): Think that quitting smoking is an economic and social investment for your } \\
\text { family, friends, and health } \\
\text { Male, } 53 \text { years old: I keep fighting this for my family and my health }\end{array}$ \\
\hline
\end{tabular}


the participants had high nicotine dependence, it remains unknown whether these preliminary results (eg, levels of interactivity and cessation) can be generalized to Latino smokers with high nicotine dependence. Moreover, three participants experienced carrier blockage that did not allow them to receive text messages. Future studies should devise methods to resolve carrier blockage at enrollment in the program, such as disabling short code blocking in cellphone devices. Despite these limitations, the study suggests that this program holds promise for further testing, including an effectiveness analysis.

Future steps include culturally and linguistically adapting Kick Buts through focus groups with Latino smokers. In addition, with the help of a Community and Communication Advisory Board, evaluating the text message library for relevance to the Latino language, culture, clarity, and readability is an important next step.

Kick Buts is a promising smoking cessation intervention for Latino smokers if tailored culturally and linguistically. This program has the potential to reach those who may otherwise not have access to traditional evidencebased smoking cessation interventions.

\section{Acknowledgments}

This work was supported by a Clinical and Translational Science Award (CTSA) grant from the National Center for Advancing Translational Sciences (NCATS) awarded to the University of Kansas Medical Center for Frontiers: The Heartland Institute for Clinical and Translational Research (\#UL1TR000001). The contents are solely the responsibility of the authors and do not necessarily represent the official views of the US National Institutes of Health (NIH) or NCATS.

This study would not have been possible without the help from our research team (Kendra Cruz, MPH; Mitzi Ramirez, BS; and Drew Cox, BS), our community health workers (Catalina Reyes, Lucia Martinez, and Norma Molina), and Agile Health Inc., the text messaging company (Gary Slagle, Scott Werntz, Vova Kagan, and Julieta Rodriguez).

An abstract of this paper was presented at the 22nd Annual Meeting of the Society for Research on Nicotine and Tobacco as a poster presentation with interim findings. The poster's abstract was published in the Society for Research on Nicotine and Tobacco 2016 Rapid Response Abstracts, and is available at: https://cdn.ymaws.com/www.srnt.org/resource/resmgr/ Conferences/2016_Annual_Meeting/Program/SRNT_2016_ Rapids_WEB2.pdf.

\section{Disclosure}

The authors report no conflicts of interest in this work.

\section{References}

1. U.S. Department of Health and Human Services, Centers for Disease Control and Prevention, National Center for Chronic Disease Prevention and Health Promotion, Office on Smoking and Health. The Health Consequences of Smoking: 50 Years of Progress. A Report of the Surgeon General. Atlanta, GA: U.S. Department of Health and Human Services; 2014.

2. Houston TK, Scarinci IC, Person SD, Greene PG. Patient smoking cessation advice by health care providers: the role of ethnicity, socioeconomic status, and health. Am J Public Health. 2005;95(6):10561061. doi:10.2105/AJPH.2004.039909

3. Cupertino AP, Cox LS, Garrett S, et al. Tobacco use and interest in smoking cessation among Latinos attending community health fairs. $J$ Immigr Minor Health. 2011;13(4):719-724. doi:10.1007/s10903-0109404-y

4. Whittaker R, McRobbie H, Bullen C, Rodgers A, Gu Y. Mobile phone-based interventions for smoking cessation (Review). Cochrane Database Syst Rev. 2012;11:1-52.

5. Kong G, Ells DM, Camenga DR, Krishnan-Sarin S. Text messagingbased smoking cessation intervention: a narrative review. Addict Behav. 2014;39(5):907-917. doi:10.1016/j.addbeh.2013.11.024

6. Free C, Phillips G, Watson L, et al. The effectiveness of mobilehealth technologies to improve health care service delivery processes: a systematic review and meta-analysis. PLoS Med. 2013;10(1):1-26. doi:10.1371/journal.pmed.1001363

7. Free C, Knight R, Robertson S, et al. Smoking cessation support delivered via mobile phone text messaging (txt2stop): a single-blind, randomized trial. Lancet. 2011;378(9785):49-55. doi:10.1016/S01406736(11)60701-0

8. Rodgers A, Corbett T, Bramley D, et al. Do u smoke after txt? Results of a randomised trial of smoking cessation using mobile phone text messaging. Tob Control. 2005;14(4):255-261. doi:10.1136/tc.2005.011577

9. Abroms LC, Boal AL, Simmens SJ, Mendel JA, Windsor RA. A randomized trial of Text2Quit: a text messaging program for smoking cessation. Am J Prev Med. 2014;47(3):242-250. doi:10.1016/j. amepre.2014.04.010

10. Op Den Akker H, Cabrita M, Op Den Akker R, Jones VM, Hermens HJ. Tailored motivational message generation: a model and practical framework for real-time physical activity coaching. J Biomed Inform. 2015;55:104-115. doi:10.1016/j.jbi.2015.03.005

11. U.S. Census Bureau 2010. Race and ethnicity. U.S. Census Bureau; 2010. Available from: https://www.census.gov/mso/www/training/ pdf/race-ethnicity-onepager.pdf. Accessed July 3, 2019.

12. Anderson M Technology device ownership: 2015. Pew Research Center; 2015. Available from: http://www.pewinternet.org/2015/10/ 29/technology-device-ownership-2015. Accessed July 3, 2019.

13. Fu SS, Rothman AJ, Vock DM, et al. Program for lung cancer screening and tobacco cessation: study protocol of a sequential, multiple assignment, randomized trial. Contemp Clin Trial. 2017;60:86-95. doi:10.1016/j.cct.2017.07.002

14. Michie S, Free C, West R. Characterising the 'Txt2Stop' smoking cessation text messaging intervention in terms of behaviour change techniques. J Smok Cessat. 2012;7(1):55-60. doi:10.1017/ jsc. 2012.12

15. Benowitz NL, III PJ, Ahijevych K, et al. SRNT subcommittee on biochemical verification. Biochemical verification of tobacco use and cessation. Nicotine Tob Res. 2002;4(2):149-159. doi:10.1080/ 14622200210123581 
16. Joffe H, Yardley L. Research Methods for Clinical and Health Psychology. London, UK: Sage Publications; 2004; doi:10.4135/ 9781849209793

17. Patton MQ. Qualitative Research and Evaluation Methods. London: Sage Publications; 2002.

18. Heatherton TF, Kozlowski LT, Frecker RC, Fagerström KO. The Fagerstrom Test for nicotine dependence: a revision of the Fagerström tolerance questionnaire. Br J Addict. 1991;86:1119-1127.
19. Abroms LC, Ahuja M, Kodl Y, et al. Text2Quit: results from a pilot test of a personalized, interactive mobile health smoking cessation program. J Health Commun. 2012;17(Suppl1):44-53. doi:10.1080/ 10810730.2011.649159

20. Cupertino AP, Cartujano-Barrera F, Ramírez M, et al. A mobile smoking cessation intervention for Mexico (Vive sin Tabaco ... ¡Decídete!): single-arm pilot study. JMIR Mhealth Uhealth. 2019;7(4):e12482. doi:10.2196/12482

\section{Publish your work in this journal}

Patient Preference and Adherence is an international, peer-reviewed, open access journal that focusing on the growing importance of patient preference and adherence throughout the therapeutic continuum. Patient satisfaction, acceptability, quality of life, compliance, persistence and their role in developing new therapeutic modalities and compounds to optimize clinical outcomes for existing disease states are major areas of interest for the journal. This journal has been accepted for indexing on PubMed Central. The manuscript management system is completely online and includes a very quick and fair peer-review system, which is all easy to use. Visit http:// www.dovepress.com/testimonials.php to read real quotes from published authors. 